\title{
Prioritising research and dissemination: a Delphi study of NHS Highland midwives
}

\author{
Kathleen Irvine, Wendy Jessiman, Alison Felce
}

\begin{abstract}
This paper reports on a Delphi study undertaken by a health librarian and two midwifery professionals, to determine the research priorities of midwives working in NHS Highland. Six important topics were identified: workforce issues, second stage of labour, obesity in pregnancy, women's expectations of pregnancy and of childbirth, place of birth, and breastfeeding. Related evidence was examined to identify topics where dissemination of existing evidence was needed. The study dealt both with the practice of midwifery in general and with the information needs of local midwives in particular. The Delphi technique was found to be a useful method to determine research priorities but it was not without its limitations.
\end{abstract}

\section{Introduction}

NHS Highland serves the largest, most sparsely populated part of the UK. The area is in excess of $32,000 \mathrm{~km}^{2}$, around $41 \%$ of the land mass of Scotland, with large areas of mountainous terrain and many island communities. Transport and communications infrastructure is poor. Providing midwifery services to such a remote and rural region affords unique challenges but it remains NHS Highland policy that "[w]omen from these areas should be offered equitable access to maternity services" (Bryers and May, 2010). The area is served by approximately 280 midwives working in a variety of settings.

\section{Authors}

Kathleen Irvine is Subject Librarian at Highland Health Sciences Library serving the University of Stirling School of Nursing, Midwifery and Health (Highland Campus) and NHS Highland personnel.

Wendy Jessiman is Lecturer in the School of Nursing, Midwifery and Health at the University of Stirling, Highland Campus and a Supervisor of Midwives.

Alison Felce is a staff midwife working for NHS Highland based at Raigmore Maternity Unit, Inverness

Email: k.y.irvine@stir.ac.uk 
It is essential that midwifery practice is based on knowledge and research (Nursing and Midwifery Council, 2010; Midwifery 2020 UK, 2010). The Health Plan for Scotland, Our National health: a plan for action, a plan for change (Scottish Executive Health Department, 2000), emphasised the importance of research and evaluation to deliver a 'responsive, effective, learning health service'. While the professional literature in midwifery provides evidence for care-giving (Ross et al., 2004), much of midwifery research is done in universities: it is therefore strongly influenced by the universities' research performance management exercises (formerly the Research Assessment Exercise and now the Research Excellence Framework), and is published in academic rather than practice-focused journals. Consequently, dissemination of this research to practising midwives may be poor or findings may be of limited relevance in clinical contexts (Fyffe, 2006). In this climate, there is a desire, locally and nationally, to encourage practitioners to integrate research into their practice. However, if strategic priorities are not specified, such research is likely to be ad hoc, inappropriately targeted and poorly disseminated; and limited resources will be wasted. Research currently carried out by NHS Highland is informed by Scottish Government Health Department priorities (Scottish Government Health Department, 2002). While this top-down approach has some merit, a practitioner-derived strategy has distinct advantages, principally its propensity for developing practical, service-driven questions of local relevance and the encouragement of local practitioners to take an interest in research and perhaps even to carry it out.

\section{Aim and objectives}

The aim of this study was to determine how clinical research might be made most useful to midwives working for NHS Highland.

Its objectives were:

i. to identify the questions which practising midwives thought needed to be answered by means of research-evidence;

ii. to determine the areas for new research that are most important for practising midwives;

iii. to determine where better dissemination of existing research-evidence to practising midwives is required.

\section{Literature review}

The Delphi Technique is a well-established consensus method for identifying research priorities and has frequently been used in healthcare contexts (Rushforth, 2007). A search of CINAHL (the major nursing and allied health bibliographic database) using a keyword search, Delphi, returned 1759 'hits' of these 258 records contained the phases 'research priorit*' or 'research agend*'. Of these, only 2 were specific to midwifery. Re-running the search on research priorities in midwifery ignoring the methodology (Delphi) returned 7 results, but only 4 of these were specific to midwifery (the others used the phrase 'nursing and midwifery' but on closer examination were found to focus on nursing). Rerunning the search in MIDIRS (the major database indexing the midwifery 
literature) returned 5 'hits', including four potentially useful papers, two of which had been missed by the CINAHL search as they did not use the term midwifery (being on parenting and child health issues). A search of Google Scholar identified one important additional study (McCourt and Beake, 2000) that had been published as grey literature. A search of LISTA provided useful background information on the role of librarians in healthcare research and in supporting evidence-based practice.

Few studies focused on the research priorities of midwives, and only two were British (Sleep et al., 1995; McCourt and Beake, 2000). By contrast, there were several more recent Australian studies (Fenwick et al., 2006; Reid et al., 2007; Hauck, Kelly and Fenwick, 2007) and one Irish study (Butler et al., 2007). The Delphi technique is the favoured methodology in most of these studies, the only exceptions being the study by Reid et al. (2007) that used a single questionnaire method, and the study by McCourt and Beake (2000) that used a face-to-face discussion method (nominal group technique).

Some studies focused on the opinions of practitioners (Fenwick et al., 2006; Hauck, Kelly and Fenwick, 2007); others sought views more widely (Butler et al., 2007; McCourt and Beake, 2000).

Delphi studies alone are insufficient to inform a research agenda, however, as they may identify areas where the evidence base is already strong, potentially leading to wasteful duplication of research effort. Of the papers identified, only four studies made any effort to link the priorities identified to the current knowledge base. Three of these papers proved particularly interesting from a librarian's point of view. The first of these is Kirkwood, Wales and Wilson's 2003 study of Glasgow nurses, where health librarians led the research and underpinned the consensus findings with a systematic evaluation of existing research. Secondly, a study by Burns et al. (2003) working in the field of rehabilitation medicine, used the Delphi technique to identify topics for evidence-based review. The third study by McCourt and Beake (2000) identified topics that might be important research questions and those that might be important topics for evidence reviews.

\section{Method}

The Delphi technique is a method of formulating a group judgement on a subject and provides a means of reaching a consensus among a group of experts (Landeta, 2006). It is normally conducted as a postal (or email) survey that solicits individual, anonymous responses to written questions. It is an iterative process involving a series of questionnaires, analysis, and feedback to each participant on the responses of the whole group (see Figure 1). The responses are analysed statistically in terms of their means and variance to determine which questions have achieved consensus. 


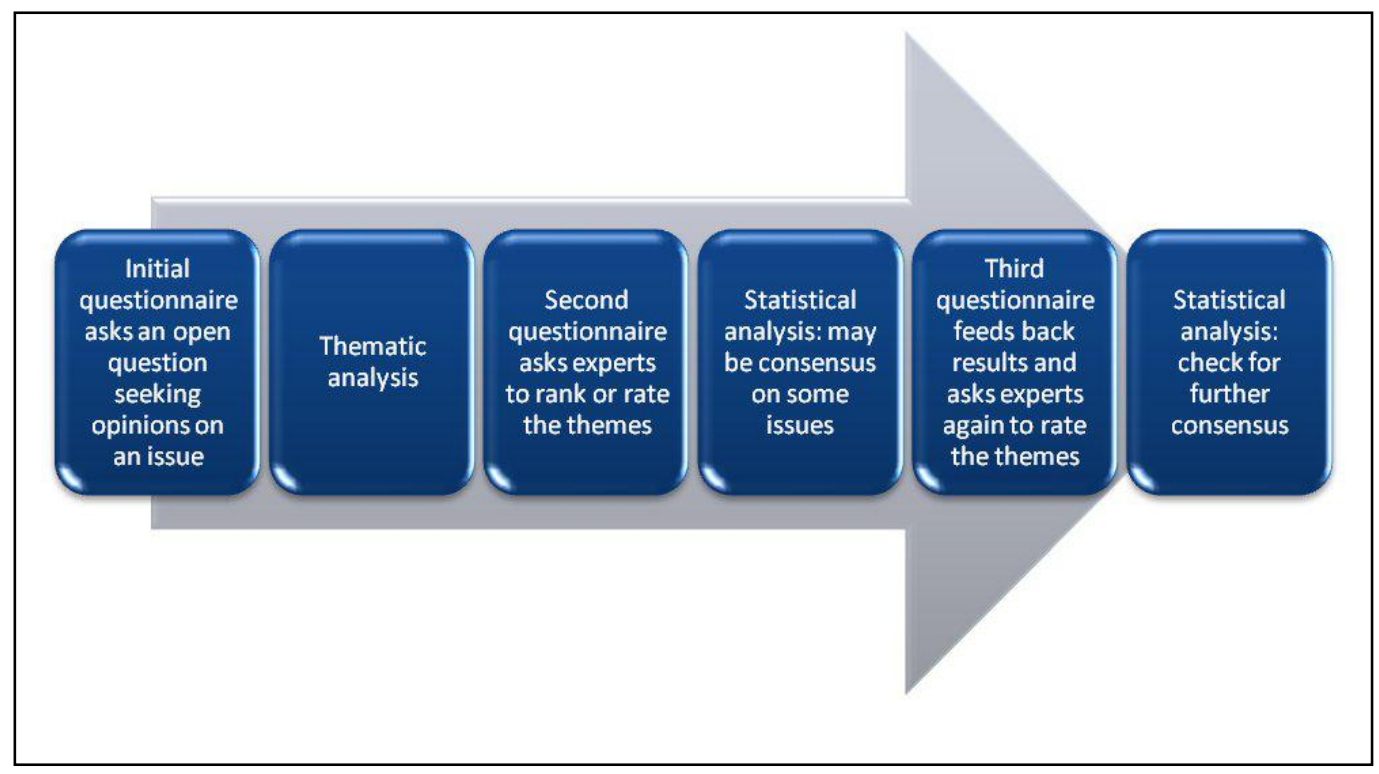

\section{Figure 1: Stages in a Delphi study.}

Originally designed to forecast events, the Delphi method is now used to explore and resolve issues across a wide range of disciplines including in librarianship (Bartlett and Casselden, 2011) and, extensively, in healthcare (Powell, 2003; Keeney, Hasson and McKenna, 2011). It may be used wherever policy or planning decisions are to be based on informed opinion, since it allows benefit to be gained from subjective judgements (Yousuf, 2007).

This method of eliciting opinion is simple, inexpensive to administer, and is useful if, for whatever reason, meetings cannot be held. It affords flexibility to participants as they can complete and return questionnaires at their own convenience (within time limits set by the researcher), although it does require time and commitment from group members. The anonymous nature of the process has advantages: participants are likely to be more willing to give their honest opinion and to be less anxious about being controversial than they might be in focus groups or other meetings; and strong personalities cannot dominate the group or lead opinion, and the 'bandwagon effect' is minimised (Yousuf, 2007). However, it has been suggested that anonymity makes participants less accountable (Mamaril et al., 2009).

The Delphi technique has sometimes been criticised for an apparent lack of scientific rigour, though Landeta (2006) found it to be a valid instrument for supporting decision making. The main assumption of the technique is that group opinion is more valid and reliable than individual opinion; but it has been argued that the apparent consensus is merely a compromise position, as extreme opinions are ignored (Yousuf, 2007).

Conventionally, Delphi studies seek the views of a panel of experts. It has been acknowledged that defining an 'expert' and selecting a panel can be difficult for researchers; the process may also be methodologically unsound (Keeney, McKenna and Hasson, 2011). There is no agreed optimum size of panel: typically 
it will normally have from ten to fifty members, but may in some circumstances have hundreds or even thousands of members (Mullen, 2003). Kirkwood, Wales and Wilson (2003), for example, sought the views of all 2984 nurses in one Glasgow NHS Trust.

In general, questionnaire research is notorious for its low response rates, and the use of multiple rounds of questionnaires (and their associated reminders) make the Delphi particularly susceptible to both low uptake and attrition between rounds (Keeney, Hasson, McKenna, 2006). It has been suggested by Mullen (2003) that a $70 \%$ response rate is required. However, this is rarely achieved in practice (Keeney, McKenna and Hasson, 2011), and is arguably only achievable where a small expert panel is appointed. It is interesting to note that Kirkwood, Wales and Wilson (2003) in their study of Glasgow nurses, that also targeted an entire professional workforce, achieved only $15.8 \%$ participation at the first round.

The present study sought the views of all NHS Highland midwives working at all grades and roles $(n=280)$ as they were expected to have expert knowledge of the midwifery issues (both local and general) that might be addressed through research. As well are requiring participants to understand the topic being investigated, it has been noted that the findings from a Delphi study are strengthened when panellists who would be directly affected by the outcomes are included (Mamaril et al., 2009). The focus on practising midwives was felt to be important, as practitioner-derived questions have been found to be concrete, practical and to provide an important service focus (Booth, 2008). It was hoped that their involvement might encourage midwives to 'take ownership' of the research findings.

Ethical consent was obtained from University of Stirling, from the local NHS Research and Development Office and from the North of Scotland Research Ethics Committee. Despite not involving patients, the process of obtaining consent from the NHS was rigorous and, at times, unsuited to a study involving only staff. Negotiation was required to have the phrase "I consent to your contacting my GP" removed from the standard consent form.

A three-round model was chosen. This is the conventional Delphi method, though some studies omit the third round (Cape, 2004) and others continue adding rounds until a desired level of consensus is reached (Holey et al., 2007). Three rounds are sufficient to allow feedback and revision of responses but not so numerous as to risk increasing attrition as fatigue sets in among respondents (Mullen, 2003).

In Round 1, an invitation to participate in the study, with a questionnaire and consent form for completion, was sent via email and internal mail to all midwives employed by NHS Highland. Despite some discussion in the literature of the merits of using email, namely speed and reduced cost (Bartlett and Casselden, 2011), this study found this approach to be almost completely ineffective: it received only one response. All other respondents used the forms sent by 'snail mail'. Poor ICT infrastructure at the time of the study, particularly - but not exclusively - for community midwives working in rural areas, may partly account for the poor response to email. 
A pilot questionnaire was trialled with student midwives and found to be suitable, though one minor difficulty emerged. The questionnaire asked respondents to identify up to five questions that they considered important topics for research. Providing five boxes for questions led some to believe they were being asked to provide, contrary to the written instruction, no fewer than five questions, something many found difficult. To solve this, the words up to 5 were then given in bold face. However, the same problem arose with the 'live' questionnaire and further publicity had to be circulated stressing that even a single question would be of interest to the research team.

To encourage participation, a midwife practising in the clinical areas was brought onto the team. It was important that she was a hands-on practitioner and not a manager as this was considered more likely to encourage 'buy-in' from her peers as well as providing the team with an important professional perspective. The support of the local head of midwifery services, who assisted in publicising the project and wrote the letter of invitation to participate, was considered similarly important.

Aware of the potential challenges they faced in recruitment, the research team put considerable effort into publicising the study. An extensive range of communication and publicity approaches was used before and during the study (see Table 1), and feedback showed that awareness of the project was very good, even among midwives working in very remote areas.

\begin{tabular}{|l|l|l|}
\hline Prior to recruitment & On recruitment & During the survey \\
\hline $\begin{array}{l}\text { Collaboration with lead } \\
\text { midwives and supervisors } \\
\text { of midwives in publicising } \\
\text { forthcoming survey; area } \\
\text { ambassadors recruited. }\end{array}$ & $\begin{array}{l}\text { Midwives received } \\
\text { personally addressed } \\
\text { envelopes in their place of } \\
\text { work inviting participation } \\
\text { and completion of the } \\
\text { questionnaire. }\end{array}$ & $\begin{array}{l}\text { Certificates given to } \\
\text { midwives on completion of } \\
\text { each round to acknowledge } \\
\text { their contribution. }\end{array}$ \\
$\begin{array}{l}\text { Article in NHS Highland } \\
\text { Newsletter. }\end{array}$ & $\begin{array}{l}\text { Visits to clinical areas in } \\
\text { support of survey. }\end{array}$ & $\begin{array}{l}\text { Regular visits to clinical } \\
\text { areas to ensure midwives } \\
\text { had received their envelope } \\
\text { and to encourage } \\
\text { completion. }\end{array}$ \\
$\begin{array}{l}\text { Use of a specially designed } \\
\text { identifiable logo and } \\
\text { dedicated Facebook and } \\
\text { Twitter pages. }\end{array}$ & $\begin{array}{l}\text { Dedicated post-boxes in } \\
\text { many areas for returning the } \\
\text { questionnaires. }\end{array}$ & $\begin{array}{l}\text { Extended the deadline for } \\
\text { returns. }\end{array}$ \\
$\begin{array}{l}\text { Use of established } \\
\text { distribution list within NHS } \\
\begin{array}{l}\text { Highland to publicise the } \\
\text { research. }\end{array}\end{array}$ & $\begin{array}{l}\text { Posters highlighting the } \\
\text { certificates available for } \\
\text { those completing the } \\
\text { questionnaire. }\end{array}$ & $\begin{array}{l}\text { Posters reminding and } \\
\text { updating midwives on } \\
\text { progress; use of plasma } \\
\text { screen adverts where } \\
\text { available. }\end{array}$ \\
\hline
\end{tabular}

Table 1: Actions to recruit and to retain participants. 
The questions elicited in Round 1 were categorised by the project researchers by hand, in much the same way as Sleep et al. (1995): each data sheet was photocopied and the individual topics guillotined into separate strips and the strips grouped into categories by the research team.

In Round 2, respondents were asked to rank the derived categories on a Likert scale of $1-5$, where a rating of 1 would indicate that the issue was regarded as unimportant and 5 as very important.

In Round 3, participants from Round 2 were asked to examine the remaining categories from Round 2 (that is, those on whose importance the participants had not agreed) and their mean importance-ratings, and were reminded of the importance-ratings that they themselves had originally given to these categories. They were asked to re-assess their rating in the light of the views of the other participants. This stage is sometimes omitted from Delphi studies but it does allow for convergence of opinion and therefore consensus.

\section{Data analysis}

The data from Round 1 were the questions or issues suggested by midwives as important topics for research. These were copied onto individual slips of paper and the slips grouped into categories by the research team.

The data from Round 2 were the ratings given to each category by participating midwives: these were analysed using descriptive statistics. The median scores and interquartile ranges (IQR) for each category were calculated. As the IQR covers the middle $50 \%$ of the data it was favoured over using the mean as it reduced the influence of outlying data that could have skewed the results. The closer the clustering of values around the median, the smaller the IQR, thus an IQR of 1 and a high median value indicated a strong consensus of positive opinion. Where the median score was 4 or over and the IQR equal to 1 , effectively when $75 \%$ of respondents had rated the category as 'important' or 'very important', consensus on priority status was deemed to have been achieved. Round 3 repeated this process to allow for possible convergence of opinion. 


\section{Results}

A summary of the study is given in Figure 2.

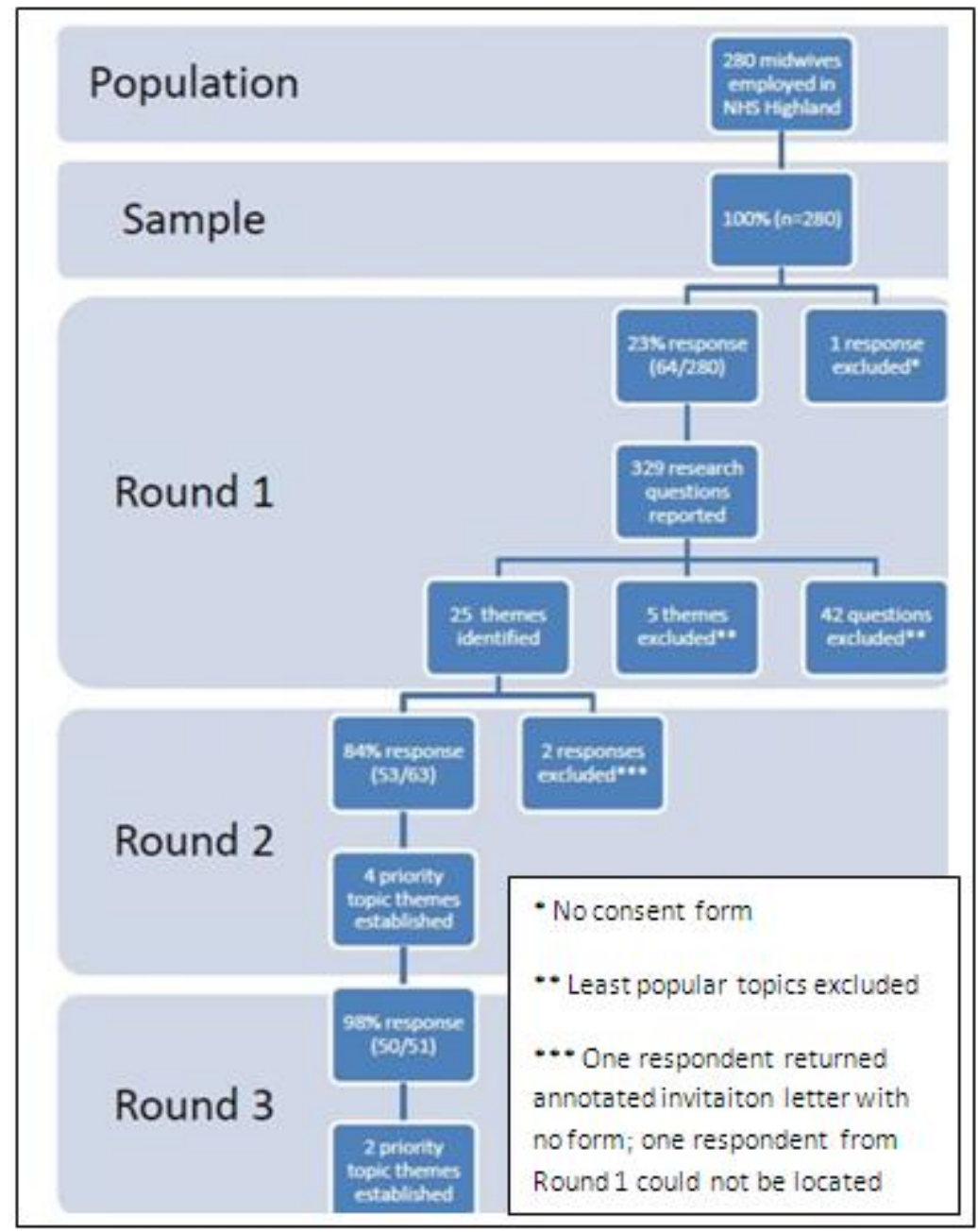

\section{Figure 2: How the study proceeded.}

Of the 280 midwives contacted, 65 returned questionnaires, of which 64 were included in the study (one had to be excluded as the respondent failed to provide a completed consent form). This was a $23 \%$ response rate, which was disappointing, but typical for this kind of study (Keeney, McKenna and Hasson, 2011).

NHS Highland is broken into four Community Health Partnerships (CHPs). The responses from each CHP were roughly in proportion to the number of midwives working in each area. Six respondents failed to provide information on their work location, and one stated that she worked in all CHPs.

The age distribution of respondents closely reflected that of the midwife population within NHS Highland and across Scotland (see Figure 3). It is interesting to note that older midwives seem just as interested in research as their younger colleagues. 


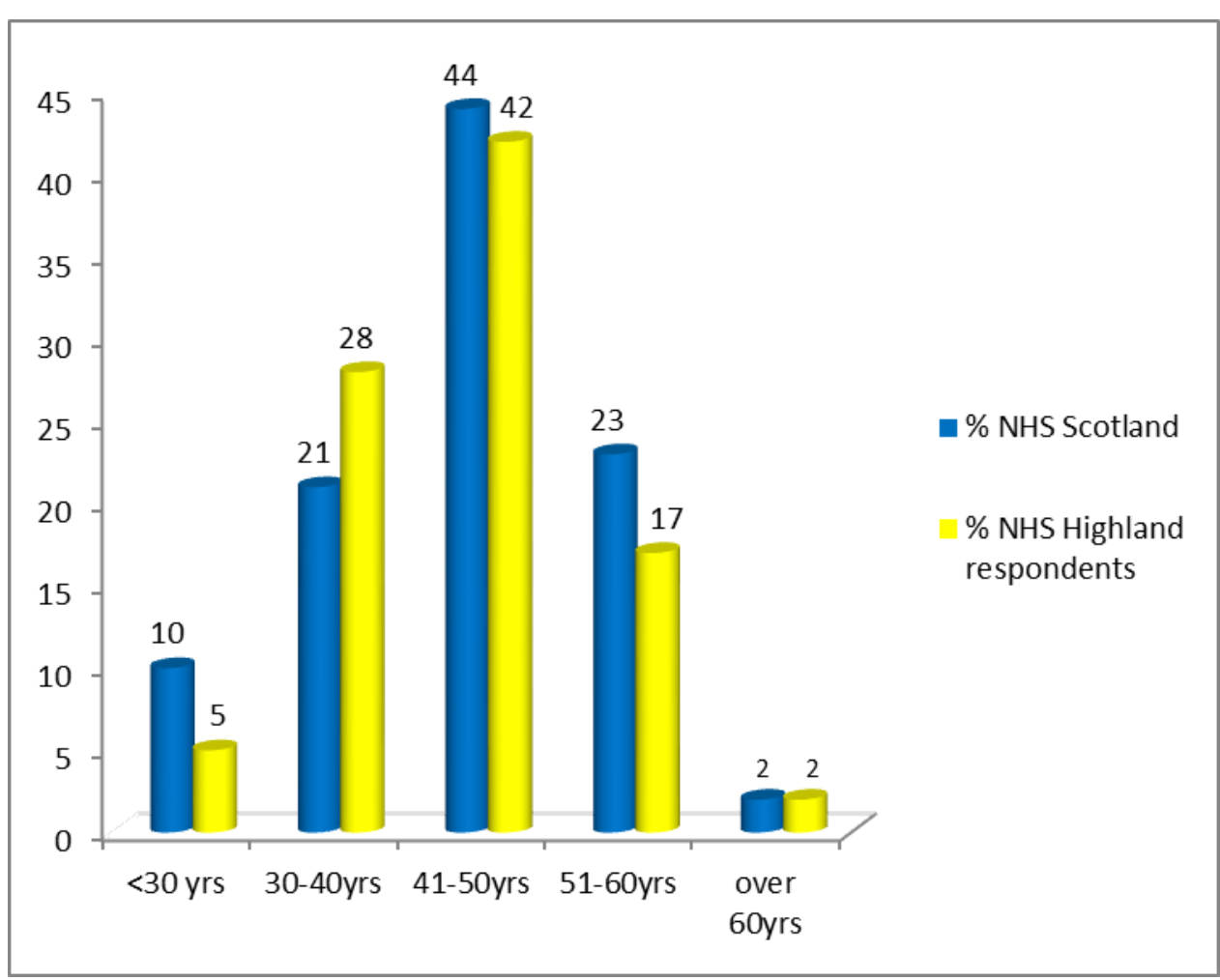

Figure 3: Age distributions of participants and of Scottish midwives in general.

The Round 1 returns provided 329 research questions. The research team organised the responses into 25 themes, with 42 questions being excluded as not falling under a theme. The five least popular themes were then excluded; they each contained no more than three research questions and were therefore considered unlikely to be judged priority topics for research. Thus twenty themes were included in the Round 2 questionnaire as possible research priorities.

$84 \%$ of Round 1 participants returned Round 2 questionnaires. In Round 2 the midwives agreed that research should be carried out on four themes: workforce issues, second stage of labour, obesity in pregnancy and women's expectations. 98\% of Round 2 participants returned Round 3 questionnaires. In Round 3 the midwives agreed that research should also be carried out on two more themes: breastfeeding and place of birth (see Table 2).

\begin{tabular}{|l|l|l|l|}
\hline Theme/area & Mean rating* & Median rating $\dagger$ & IQR $\dagger$ \\
\hline Workforce issues & 4.5 & 5 & 1 \\
Labour, second stage & 4.4 & 5 & 1 \\
Obesity in pregnancy & 4.2 & 4 & 1 \\
Women's expectations & 4.1 & 4 & 1 \\
Place of birth & 4.1 & 4 & 1 \\
Breastfeeding & 4.0 & 4 & 1 \\
\hline \multicolumn{2}{|r|}{ *In Round 1 $†$ On achieving consensus }
\end{tabular}

Table 2: Categories achieving consensus. 


\section{Research evidence on the themes identified}

The themes were very broad, but of course contained particular questions suggested by midwives in Round 1. Within the themes it was possible to identify sub-themes, into which the original questions could be grouped (see Figure 4). Searching the published evidence was done initially at sub-theme level with further searches often being needed to ensure that particular questions were considered.

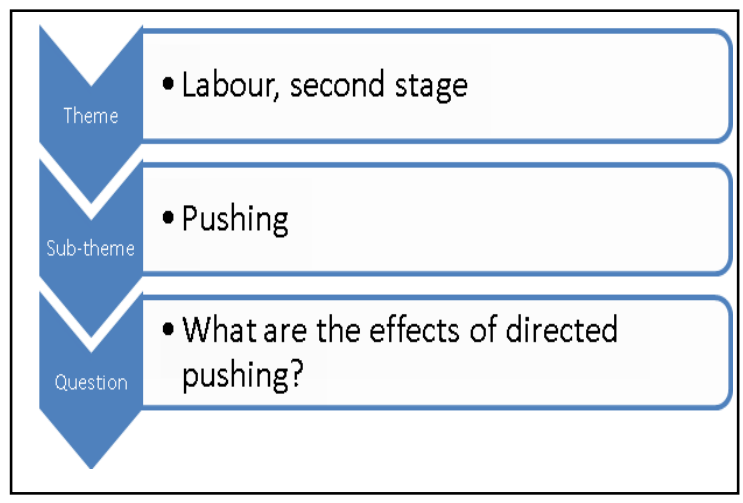

Figure 4: Topics considered as themes, sub-themes and questions.

Papers were identified from searches of bibliographic databases including The Cochrane Library databases, MEDLINE, MIDIRS, Maternity and Infant Care, CINAHL and Web of Knowledge. Point of Care tools that seek to summarise evidence were also checked: Dynamed, Up-to-Date, Nursing Reference Center and the Joanna Briggs Institute. TRIP database was used to identify national guidelines. More specialist resources, such as British National Formulary, and additional databases were consulted when appropriate.

Evidence from systematic reviews, meta-analyses or meta-syntheses (known as 'Level I evidence') was sought in all cases. Such studies provide a synthesis of the best evidence, so are highly regarded in healthcare. They aim summarise all high quality studies on a topic and increasingly are used to inform clinical decision making (Cook, Mulcrow and Haynes, 1997). Where such studies were not identified, or where they were inadequate to answer the questions raised, searches for other study types were conducted. Randomised controlled trials ('Level II evidence') were searched for to questions concerned healthcare interventions, since they are commonly regarded as providing evidence of effectiveness (Evans, 2003). Sometimes lesser evidence from observational studies was the best available: these studies were cited in the dissemination report but with a note concerning their limitations.

Many of the questions posed, however, did not concern interventions, so other types of papers, such as those reporting qualitative research, were sought where appropriate. Local evidence from clinical audits and also local and national guidelines were cited in the dissemination reports.

The themes often contained particular questions which did not fall under any subtheme. It was not practicable to search for evidence that might answer these questions. 


\section{Discussion}

Few previous studies have examined the research priorities of midwives and only two of these were conducted in the UK. No study was identified that involved midwives in Scotland. The current study throws light on the research priorities and information needs of midwives working in NHS Highland.

There was consensus among the midwives that participated that more research is needed in six areas: workforce issues, second stage of labour, obesity in pregnancy, women's expectations, place of birth and breastfeeding. To an extent these themes echo those of previous similar studies, with the exception of obesity in pregnancy which did not emerge in earlier studies of midwives' priorities. As this is an emerging health concern, it is perhaps unsurprising to find that currently midwives, at least those in NHS Highland, consider research on this topic to be an important priority.

One of the British studies (Sleep et al., 1995) shared some findings with the present study. Second stage of labour (aspects of which fill three of their top twenty topics), Satisfaction, Audit and choice: giving women choices and Midwifery management: staffing issues are among Sleep's top twenty topics, and are similar to three of the present study's priority topics, i.e.: Second stage of labour, Women's satisfaction and Workforce issues. Place of birth, that emerged as one of the six priority topics in NHS Highland, was mentioned under the topic heading Role of the midwife: midwives' ability to respond to recent changes. The other Highland priority topics - Breastfeeding, and Obesity in pregnancy - did not appear in the Sleep's top twenty.

McCourt and Beake (2000), who focused on maternity services in primary care settings, identified two priority questions on homebirth and one on community support for breastfeeding; otherwise their findings were dissimilar to those of the NHS Highland study.

A more recent Irish study (Butler et al., 2009) identified six priority issues of which Satisfaction with care was the only one that paralleled the present study's findings.

This study faced a major obstacle in encouraging participation from midwives. In spite of the considerable efforts made to recruit midwives to the study, participation remained stubbornly low and the reliability of the results as a representation of the opinion of Highland midwives may be questionable. However, it has been argued that a large panel will often contain more diverging opinions, and that the accuracy and generalisability of the findings of a Delphi study based on such a panel may suffer in consequence (Keeney, McKenna and Hasson, 2011). While the initial response rate was disappointing, it is worth noting that attrition rates in subsequent rounds, often a problem in Delphi studies (Keeney, McKenna and Hasson, 2011), were very low. The research team attribute this to achieving "buy-in" from participants by judicious promotion of the study, the use of personal reminders and of social networking to sustain interest.

While the demographic characteristics - particularly the ages and locations - of the participating midwives were similar to the those of Scottish midwives in 
general, it does not necessarily follow that the opinions that the participants expressed would be echoed by every Scottish (or indeed every British) midwife. Dissatisfied midwives, for example, might be more likely to respond to a study (with questions reflecting that discontent) than those happy with their lot. Better educated midwives, being perhaps more interested in clinical research, are also likely to be over-represented in the sample (Davies et al., 2003)

Broad themes have a tendency to emerge in Delphi studies (Kennedy, 2004) and, arguably, in all consensus exercises: this study was no exception. It could be argued that the themes were too wide to be of practical value and that the subthemes were the truly useful units of analysis and priorities for possible research. However, using these sub-themes as the categories presented to participants may have been impractical, resulting as it would in a very large list for participants to evaluate. This is likely to have resulted in poorer response rates and higher attrition.

Although six priority categories were identified by the study, one over-arching theme became apparent across the derived categories without itself being identified as a category: that of place. Frequent use of the words 'here' or 'in Highland' or 'remote' or 'rural' was observed. This may be interpreted as indicating concern that practices which work well in urban settings might be unsustainable, impractical or otherwise inappropriate in NHS Highland. Further research, possibly with focus groups of rural midwives, would be needed to explore these questions further.

The importance of 'place' may in fact make the third objective of this study difficult or impossible to achieve: it may do no good to disseminate the findings of research done elsewhere if the problem at hand has arisen from special conditions in the Scottish Highlands. When a midwife asks 'Does the Baby Friendly Initiative work in Highland?' giving her evidence of the effectiveness of the initiative from studies conducted around the world is unlikely to be satisfactory: she has probably heard it all before.

The enormity of the dissemination phase had been under-estimated at the outset. Scores of searches of the literature were undertaken and hundreds of papers were read. The papers were quickly appraised to determine their practical usefulness and whether they answered the questions posed. Consideration was given to the level of evidence, but a full evaluation of how well the research had been conducted was not possible due to the volume of the task and limited resources of the team. Here the study fell short of the highest standards of evidence based practice.

It had been anticipated that midwives' ignorance of the research literature might result in their selecting as priority topics subjects already well studied. In fact, this may not have been the case, for while some well-supported interventions did emerge, it was often in the context of local issues. Further, midwives sometimes asked questions that reflected recent controversies that had been aired in the professional literature, suggesting that many are interested in research findings.

The basic assumption of the Delphi method is that group opinion is more valid than individual opinion; but this assumption may not always be correct. It is 
possible that the best questions may not always be the most popular ones and good questions may become subsumed by wider themes that are subsequently discarded by the process. Many questions, often interesting ones, were discarded as they were unique or unusual among the suggestions made.

\section{Conclusion}

This study provides midwives, policy makers and researchers with a range of questions about midwifery services and practice of importance to Highland midwives that may be answered by research. It establishes research priorities that may inform future research efforts for NHS Highland and offer guidance for individual midwife-researchers who are interested in conducting these studies. Beyond the six research priority topics, this study has highlighted the importance of place (especially remoteness and rurality) as a possible complicating factor to be considered when implementing evidence-based guidelines; itself an observation that would benefit from further exploration.

It has been observed that 'the majority of professional papers identify priorities without assessing the level of evidence already available to inform practice' (Ross et al., 2004) and it is recognised that the skills of health librarians have been underutilised in this area (Brice and Muir Gray, 2004). While the initial premise that topics well supported by existing evidence could be addressed by dissemination to practitioners proved to be simplistic, the skills of the health librarian within the research team proved useful in identifying and appraising the evidence that touched on the priority topics. It is hope that the resulting publication of the questions raised alongside summaries of the evidence surrounding them will be useful and interesting to midwives across the region.

This study has demonstrated that it is possible to use the Delphi method to reach consensus on a complex issue and it is a methodology within easy grasp of a beginner researcher.

This study has demonstrated that an academic librarian can be a valuable member of a research team. It has offered an opportunity for the librarian to engage with an important group of service users; to better understand their needs and working practices. It has demonstrated the value of a librarian in the support and implementation of evidence-based practice. 


\section{References}

Bartlett, R. and Casselden, B. (2011) An investigation into the attitudes of academic librarians towards internet plagiarism of HE students, Library and Information Research, 35(110), 29-42.

Booth, A. (2008) Using evidence in practice: retrospective, Health Information and Libraries Journal, 25, 49-51.

Brice, A. and Muir Gray, J. A. (2004) What is the role of the librarian in $21^{\text {st }}$ century healthcare? Health Information and Libraries Journal, 21(2), 81-83.

Bryers, H. and May, H. (2010) Maternity services strategy. URL: http://www.nhshighland.scot.nhs.uk/meetings/boardsmeetings/documents/board meeting 2 february 2010/5.4 maternity services strategy.pdf [accessed 31.03.2012].

Burns, S. P. et al. (2003) Rehabilitation of traumatic injuries: use of the Delphi method to identify topics for evidence-based review, American Journal of Physical Medicine and Rehabilitation, 82(5), 410-414.

Butler, M. M. et al. (2007) Identifying research priorities for midwifery in Ireland, Midwifery, 25, 576-587.

Cape, B. (2004) Gathering opinion and initiating debate: the success of the Delphi method in purely qualitative research, Library and Information Research, 28(89), $35-44$.

Cook, D. J., Mulrow, C. D. and Haynes, R. B. (1997) Systematic reviews: synthesis of best evidence for clinical decisions, Annals of Internal Medicine, 126(5), 376-380.

Davies, J. et al. (2002) The research potential of practice nurses, Health and Social Care in the Community, 10(5), 370-381.

Evans, D. (2003) Hierarchy of evidence: a framework for ranking evidence evaluating healthcare interventions, Journal of Clinical Nursing, 12(1), 77-84.

Fenwick, J. et al. (2006). Priorities for midwifery research in Perth, Western Australia: a Delphi study, International Journal of Nursing Practice, 12(2), 7893.

Fyffe, T. (2006) Nursing and midwifery research in Scotland: from partnership to collaboration, International Nursing Review, 53(2), 117-122.

Hauck Y., Kelly R. G. and Fenwick, J. (2007) Research priorities for parenting and child health: a Delphi study, Journal of Advanced Nursing, 59(2), 129-139.

Holey, E. et al. (2007) An exploration of the use of simple statistics to measure consensus and stability in Delphi studies, BMC Medical Research Methodology, 7(1), 52 .

Keeney, S., Hasson, F., and McKenna, H. (2006) Consulting the oracle: ten lessons from using the Delphi technique in nursing research, Journal of Advanced Nursing, 53(2), 205-212. 
Keeney, S., McKenna, H. and Hasson, F. (2011) The Delphi technique in nursing and health research. Chichester: Wiley-Blackwell.

Kennedy, H. P. (2004) Enhancing Delphi research: methods and results, Journal of Advanced Nursing, 45(5), 504-511.

Kirkwood, M., Wales, A. and Wilson, A. (2003) A Delphi study to determine nursing research priorities in the north Glasgow university hospitals NHS trust and the corresponding evidence base, Health Information and Libraries Journal, 20, 53-58.

Landeta, J. (2006) Current validity of the Delphi method in social sciences, Technological Forecasting and Social Change, 73(5), 467-482.

Mamaril, M. et al. (2009) ASPAN's Delphi study on national research: priorities for perianesthesia nurses in the United States, Journal of Perianesthesia Nursing, 24(1), 4-13.

McCourt, C. and Beake, S. (2000) Establishing research priorities in maternity and primary care research. London: Department of Health, London Regional Office, Primary Care Studies Programme.

Midwifery 2020: delivering expectations (2010). URL: http://www.midwifery2020.org [accessed 30.03 2012].

Mullen, P. M. (2003) Delphi: myths and reality, Journal of Health Organization and Management, 17(1), 37-52.

Nursing and Midwifery Council (2010) Midwives rules and standards. Rev. ed.. London: NMC.

Powell, C. (2003) The Delphi technique: myths and realities, Journal of Advanced Nursing, 41(4), 376-382.

Reid, J. et al. (2007) Research priorities of NSW midwives, Women and Birth, 20(2), 57-63.

Ross, F. et al. (2004) Identifying research priorities in nursing and midwifery service delivery and organisation: a scoping study, International Journal of Nursing Studies, 41(5), 547-558.

Rushforth, K. (2007) Identifying research priorities: Delphi technique, Paediatric Nursing, 19(7), 10.

Scottish Executive Health Department (2000) Our national health: a plan for action, a plan for change. Edinburgh: Scottish Executive.

Scottish Government Health Department (2002) Choices and challenges - the strategy for research and development in nursing and midwifery in Scotland [online]. URL: http://www.scotland.gov.uk/Publications/2002/12/15813/13936 [accessed 31.03.2012].

Sleep, J. et al. (1995) Establishing priorities for research: report of a Delphi survey, British Journal of Midwifery, 3(6), 323-331.

Yousuf, M. I. (2007) Using experts' opinions through Delphi technique, Practical Assessment, Research and Evaluation, 12(4), 1-8. 


\section{The Occasion}

This study was possible as a result of Kathleen Irvine winning the 2010 LIRG Research Award.

\section{Acknowledgement}

The authors are grateful to LIRG for funding the research, to Dr Helen Bryers for her unstinting support of this project, to NHS Highland and University of Stirling for their facilitation and the NHS Highland midwives for their interest and participation in the study.

\section{Open access and copyright}

Library and Information Research is an open access journal. A freely available copy of this paper may be downloaded from the journal's website: http://www.lirgjournal.org.uk/lir/ojs/index.php/lir.

Copyright and associated moral rights in the works published in Library and Information Research are retained by the author(s) but this paper may be used freely, with proper attribution, in educational and other non-commercial settings. 